\title{
Eating with friends, family or not at all: young people's experiences of food poverty in the UK
}

\begin{abstract}
The paper draws on findings from a study called 'Families and Food in Hard Times', which is examining food poverty among children and families in three European countries. In the UK, qualitative interviews were carried out with 45 11-15 year olds and their parents or carers. Young people's narratives reveal food poverty as a multi-dimensional experience, including hunger, poor quality food and social exclusion. Analysis suggests a limited degree of sharing of food between young people and how they contribute to the family's management of food practices in constrained circumstances. Generally young people contest the dominant discourses which blame food poverty on individuals and families.
\end{abstract}

Key words: food, poverty, children, families, UK, qualitative

\section{Background}

The political landscape pertaining to child poverty in the UK has been shifting dramatically in recent years. Numerous reports from academic, government and non-government organisations since the mid-2000s have documented child poverty and its many ramifications including social exclusion (e.g. Attree, 2006; Sharma, 2007; Ridge, 2002; 2011). At the same time, the Child Poverty Act 2010 was repealed by the Conservative Government in 2016, with its aim to cut child poverty rates by 2020 abandoned. Deep welfare retrenchment, following the Welfare Reform Bill passed in 2012, has introduced measures including the freezing of Child Benefit, the linking of welfare benefits to the Consumer Price Index rather than the Retail Price Index and the introduction of a 'benefits cap' on the overall value of benefits a family can receive. These policies have been implemented by the Coalition and Conservative Governments from 2010, following the global financial crisis in 2008, as part of a neo-liberal austerity agenda purportedly in pursuit of decreasing the financial deficit. The effects on children of these welfare reforms, on top of the stagnation of wages and increases in precarious employment, such as zero hours' contracts for working families, have been particularly severe; evidence shows how the resulting heightened stigma and social exclusion from mainstream activities through a lack of money are extremely damaging (Ridge, 2013).

In this paper, we focus on a specific aspect of the experience of poverty for children and young people in the UK, food poverty. Evidence suggests food poverty for children has grown and continues to increase in the UK. For example, research by Lambie-Mumford and Green (2015) demonstrates that the provision of food parcels to children by charitable food banks has grown considerably since the introduction of welfare reform, austerity measures and fluctuating living costs in recent years. And a recent report from Royal College of Paediatrics and Child Health (2017) showed that the large majority of paediatricians surveyed agreed that food insecurity contributes to ill-health among the children they treat, with parents diluting milk, relying on food banks and limiting their own eating to care for their children. Despite some research on food poverty as experienced by young people in the US (Connell et al, 2005; Fram, 2011), and research about social inequalities, food and children in the UK (Wills, 2008; Fairbrother et al, 2012), research focusing specifically on food poverty for children in the UK is limited, small-scale and has generally been carried out by nongovernment organisations (eg. Harvey, 2014). This paper therefore contributes to a small but growing literature about the food and eating practices of children and young people living in low-income families. It focuses not only on what children eat but also how they eat in the 
context of their everyday lives and social relations. We demonstrate the complex and multifaceted nature of food poverty as experienced by teenagers and show how they manage their circumstances and those of their families. We also show how many of the young people contest the media and political discourses that apportion blame for food poverty on individuals and families struggling to make ends meet in a period of prolonged economic and welfare retrenchment.

In the study on which this paper is based, we draw on Townsend's seminal definition of relative poverty (1979) and define food poverty as: 'the inability to acquire or consume an adequate quality or sufficient quantity of food in socially acceptable ways, or the uncertainty that one will be able to do so' (Dowler et al 2001:12). These definitions emphasise the social participation dimension of poverty and food poverty, also termed 'alimentary participation' (Pfieffer et al, 2011), with food understood as a medium for social exclusion and inclusion. In Stone's words (1988: 71): 'eating the same food as others is a basic mark of belonging'.

\section{The Study}

The study called 'Families and Food in Hard Times' is funded by the European Research Council. It examines the extent and experience of food poverty among children and families in three European countries, including the UK. Alongside secondary analysis of large scale data, in all three countries qualitative interviews were carried out with young people (aged 11-15 years) and their parents or carers in two contrasting study areas, in the years 20152017. 45 families took part in the UK and Portugal and 43 families in Norway. In the UK, 30 of the sample lived in a London borough and 15 in an English coastal town, both areas with high child poverty rates of over $40 \%$ (after housing costs) (End Child Poverty, 2016).

The two study areas differ in terms of employment opportunities, housing costs and, demographically, the London borough is much more ethnically mixed. Both are characterised by a high density of 'fast food' outlets selling relatively cheap, energy dense foods (Maguire et al., 2015). In the London area, there is also a range of local and national supermarkets and shops as well as street markets where fresh food is readily available. There is a good public transport system and buses for local children and young people are free. In the coastal area by contrast, transport is expensive and there is a limited range of mainly low budget food shops and outlets. Both areas are undergoing gentrification, though more recently in the coastal area, which became run down during the 1970s when British seaside resorts went out of fashion.

After ethical approval was obtained from the funder and the research institution, families in both areas were recruited via a short self-completion survey sent home from three schools. This was followed by other methods of recruitment, such as referrals from local charities. Careful attention was given to ensuring ethical standards were adhered to in the research process. For example, obtaining informed consent was seen as an on-going process: parents were asked for their own consent and for permission to seek the child's consent to participate, prior to carrying out the interview. In most cases interviews took place in the home; some parents chose to be interviewed elsewhere, such as at a trusted organisation. Information leaflets for parents and young people were provided prior to the interviews and both parents and young people were again asked for their consent before the interview began. Anonymity and confidentiality were assured, with the exception of any safeguarding concerns being raised. 
Semi-structured interviews were conducted with parents and young people and included the topics of income and outgoings, food budgets and practices, social lives regarding food and eating, sources of support and perspectives on managing and feeding the family on a low income. Whilst we sought to interview parents and children separately, housing conditions meant this was not always possible. Interviews with parents (usually mothers) lasted roughly 1.5 hours on average and with young people around 45 minutes. A subsample of families (12/45) participated in two follow up visits that involved visual methods, to learn more about foods bought and eaten at home and elsewhere and how any changes in circumstances impacted on food and eating over time (see O'Connell, 2013). These visual methods included a tour and photography of the family's kitchen and food storage areas with the parent, followed by an interview with the young person about their photos of food they had eaten recently in different settings, such as home, at friend's places and out in the neighbourhood. In most cases, and with parents' and young people's permission, interviews were recorded and transcribed verbatim.

We adopted a case study approach for analysis, in which we examined in detail each of the 45 cases of young people and their parents that constituted the sample. Initial analysis consisted of the research team developing case summaries for the parent and the child according to a set of themes in relation to the research questions. We then compared the cases, analysing the commonalities across and the differences between the cases, in relation to these themes (Gomm et al, 2000).

\section{The Young People}

In what follows, we present three cases of young people, selected from the 45 families. We have selected only three cases so that we can demonstrate, in an in-depth and nuanced way, the multi-dimensional aspects of food poverty as well as the embedded nature of food and eating in the wider context of the young people's lives. The cases are chosen to exemplify some of the poorest families across the two areas: all three are lone mother households, two currently living on benefits and, in one family, the mother has no recourse to public funds because of her legal status. Lone parents are known to be the most likely to be spending less on food than that needed to meet the Food Budget Standard as part of research into the Minimum Standard Income (O'Connell et al., in press, 2018). Moreover, the three families represent key targets of current UK public policy and public discourse: migrant households without the right to live in the UK are at risk of destitution and deportation and lone parent families, who have long been the butt of policies that have sought to reduce 'dependence' on the state (O'Connell and Brannen, in press, 2018). Pseudonyms are used throughout.

\section{Michael}

Michael is aged 15 and White British and lives with his mother. He lives in a council flat in an area of London, which has witnessed rapid change and gentrification over recent years, leading to very high house prices locally and expensive cafés and grocery shops nearby. He attends the local comprehensive school and spends most of his time outside school hours either sitting in his room, playing on the X-Box or skate boarding with friends locally or in central London.

Michael's mother has been unemployed for the past two years since losing her job and she has become increasingly depressed at her loss of income and status. They live on $£ 166$ per week, which is made up of Job Seekers Allowance, Child Tax Credit and Child Benefit; their 
rent is covered by Housing Benefit ${ }^{\mathrm{i}}$ and they spend about $£ 30$ per week on food. Michael's mother has resorted to using the local food bank twice recently because of a large gas bill and bank overdraft charges, both of which left her without enough money for food.

Michael usually skips breakfast mainly because he is in a hurry to get to school and also because he doesn't feel like eating. He receives an allocation of $£ 2$ for free school meals each day but he usually uses this at break time; he is restricted to a small sandwich because that costs $£ 1.80$ rather than the larger baguette that costs $£ 2.30$, as this is over his allowance. By lunchtime, therefore, he is hungry and because he lives only a few minutes' walk away, he goes home looking for food, but often fails to find it: 'I just come back, but sometimes there's not food so I just come back for no reason ... and then I just go back to school'. Sometimes he finds something to eat - typically instant noodles or pasta, which he has with whatever he can find, like pesto or butter. Food is more plentiful, he says, when his mother has received her benefits and done the shopping at Iceland ${ }^{\mathrm{ii}}$ : 'when my mum's been paid, there's food in the house, when she hasn't been paid there's no food in the house'.

When asked what he eats after school, Michael again describes not having enough food to eat at home: 'I just see what's in the house, look in the fridge, look in the cupboard. Look in the fridge again, hoping more food's just appeared'. Evening meals, which his mother usually cooks for him, consist of sausages, pizza, pasta or noodles: 'I just eat like pretty much the same thing'. His mother complains that he does not like the foods that she does, such as fish and vegetables, and that she often ends up making two meals. He helps himself to fruit and says 'that always gets eaten, I love fruit'. After dinner, he says he is usually hungry again and prepares himself something, often quite late at night after his mother has gone to bed typically more pasta or noodles, or a frozen burger. Michael's priority is food that is 'quick to make'. However, he has aspirations of becoming a chef, partly because he can have easy access to food: 'I just kind of like the idea of it, and I like the fact that you can just eat whenever you wanted in a restaurant.'

Currently Michael does not get pocket money, although he says he used to when he was younger (and presumably when his mother was working) but he regularly asks her for a 'couple of quid' and 'I just keep begging and hopefully money comes'. He uses the money so he can grab something to eat like a bag of chips when he goes out with his friends. If he can't get money, he says that his friends sometimes buy him something and he offers to pay them back; they 'just tell me "pay it back when you can can...cos you don't have a lot of money".'.

Buying food locally is a challenge for Michael, 'this high street is really like trendy, like you've got loads of like expensive cafs and stuff....so you can't just like go with like £2 and buy yourself food. Cos you can't...you can't get an actual loaf for £2 around here'. Although Michael said that this 'doesn't bother' him, he said that his friends 'buy paninis and stuff from the cafes for like $£ 3, £ 4$.... just don't have that money', shedding new light on why he comes home at lunchtime rather than staying out with his friends. He says he can sometimes ask people back to his home for food but emphasised this was 'just like basic food. Burgers or whatever', contrasting it to the jerk chicken he had eaten at a friend's house.

For Michael, employment is the way of improving his situation and to this end, he wants to get an apprenticeship. Similarly, when asked who he thinks is responsible for ensuring families have enough food to eat, he said he thought it was a combination of parents and those who pay wages: 'it's kind of like parents isn't it, but then parents can't really supply 
you with food if they don't have like a good job, like good work and pay. So it's kind of like parents plus like job people like... I don't know what you call them, like managers or whatever'.

\section{Charley}

Charley is age 13 and lives with her mother and her 15-year-old brother. Her mother's partner lives there some of the time. They are White British, live in a privately rented maisonette in a large Victorian house in a coastal town in England, and have lived there for about 9 months. Like much of the surrounding housing, the flats where they live are in a poor state of repair. Charley describes it as 'a bit noisy, a bit crowded-ish'. However, she has made friends with the neighbours' daughter and they walk to the local secondary school together, about a mile away; she sometimes goes there after school or stays overnight.

Charley's mother suffers from some physical health problems, which give her quite a lot of pain, and some mental health difficulties too, such as depression and anxiety. Poor health has affected her mother's ability to work and she is currently unemployed, but attending courses run by the Job Centre, as she is interested in running her own business in catering. The family's income, which is made up of Job Seekers Allowance, Child Benefit and Child Tax Credits, is $£ 277$ per week. Charley's mother pays $£ 88$ per month for her rent and the rest is paid by Housing Benefit. The food weekly budget is $£ 50$ per week on average. She enjoys cooking and grows some vegetables and fruit, such as tomatoes, courgettes and strawberries in the garden, which is shared by four flats. Both Charley and her mother take an interest in food and preparing what they consider to be healthy food: ' well mum usually has vegetables with everything we eat, which is good, because I usually eat all the vegetables'.

Charley's mother prides herself on providing meals on a limited budget and to do so, often travels on foot to three or four shops to take advantage of special offers. However, she says that good food is 'also very expensive. The better you want to eat....that's crazy to me, because it sort of makes you feel like you're in a bracket where you can eat only crap ...you'll look at the expensive stuff and you're "Oh I wish we could have that tonight". Having enough for all of them at times is a challenge and Charley's mother has had to skip meals or eat crackers for a few days to enable the children to eat, when money has been very tight. Watching their mother go without has emotional implications: 'If there isn't enough food we'll get it and sometimes mum will go hungry and starve and stuff. Even if it's not that much food for me and my brother, it's enough that we've actually had something, whereas mum hasn't, and it gets a bit to the point where we'll start feeling guilty because mum hasn't had anything and we've had it'.

Occasionally there isn't enough food for Charley and her brother, such as when there was a delay in receiving the housing benefit or when they had an unexpected bill, but her mother emphasises this was only for a few hours or 'never longer than a day'. On these occasions, Charley says that 'we mostly always have cereal'. Although her mother has not had to visit a food bank where they live currently, she did have to use one in the last town, a few months previously.

To see her friends at their homes or the shops, Charley walks long distances as she cannot afford the bus fare. Charley says her mother gives her money 'when she can' but she often doesn't have enough money to buy food when she is out with friends: 'sometimes they'll have money and sometimes they'll get me chips or something or they'll just get me something, 
which is all right cos they're nice friends and stuff. But sometimes they can't because it's like their money'. She described her recent first visit to Costa ${ }^{\mathrm{iii}}$ with some friends; although they all had 'about a tenner each', she 'didn't have money'. She told a story whereby her friends bought toasties because they were hungry and when they realised she had no money, a friend said 'I'll give you half of this if you want' but, 'I was like 'Yeah' and she ended up eating it all'.

When talking about photos of meals she had taken over a two-week period as part of the visual methods interview, Charley displayed a detailed knowledge of the prices of everything they had bought for the meal: 'we had 'Cathedral' cheese which was only $£ 1$...the ham was $45 p$ ' adding that 'it's all about all your deals and like what you can make and stuff'. She says that they mainly buy 'sale stuff' when food shopping and calls her family 'bargain hunters'. Even when Charley is with her friends, she persuades them to look for bargains with her: 'Yeah I'll be like "Come on guys, we'll go and look at the sale section"; they're like 'What?' They do really nice stuff in the sale section, I swear'.

Charley did not hesitate to say 'the government' when asked about whose responsibility she thought it was to ensure families have enough to eat. Reflecting on occasions when benefits have been delayed, she explained that 'people have to pay bills and the government know that people have to pay bills. And sometimes they could just take the money out of other people's accounts ... and it gets stupid cos if people actually need that money, and they need it for food or something, then it's their fault. And if ... for example that they need the money to get food, and they ain't able to get food, again it's their fault and they need to sort it out ... but they don't'.

\section{Kwame}

Kwame (see O'Connell and Brannen, in press, 2018) was born in West Africa and migrated to the UK at the age of nine. He is now 15 years old and lives in a two-bedroom privately rented flat (at a cost of $£ 1500$ per month) in London with his mother and two younger siblings, age 4 and 5. Until about six months ago, their mother worked full-time as a cleaner for a local hospital, a job she had done for three years and which she enjoyed and valued. She had to stop working when her legal status came under review by the UK Home Office and because of delays in her case being assessed, she has lost her right to work and entitlement to all welfare benefits, including free school meals for Kwame. The family is now facing eviction for non-payment of rent and being pursued by debt agencies for non-payment of council tax and credit card debt. For the past few months, they have been living on occasional money and food shopping from one of the children's fathers and also food from friends and the food bank.

Kwame attends the local comprehensive secondary school; he loves to play football but there is no money for him to attend a club or training. Studying is important to him as well as attending Church, which he does with his mother and siblings, normally at the weekend. Food eaten at home is mainly cereals like coco pops and rice with a stew, usually made with tomatoes. The food at home, he reports, is in short supply and also quite monotonous: 'we keep repeating the same food like over and over and over, just gets boring. Like just keep eating ... but we can't do anything about it, we have to just keep eating the same food'. 
Kwame describes the physiological sensation of the hunger he experiences as physical pain: 'I was so hungry and that, so ... all of a sudden yeah it was like ... it was like ... it was like I got hit on my belly... like I got stabbed with a knife'. He contrasts his hunger now with how they ate when he was younger: 'Yeah ...we used to like eat. But now ....we haven't eaten cos my mum's stopped working, not enough food coming ... we have to like cope with it.... and not spend nothing cos like if you do then we 're going to struggle even more'. At school, he reports that his belly is always 'rumbling' and hunger leads to a lack of energy. As a result, he falls asleep on the desk, gets into trouble and is falling behind: 'yeah cos I've done a test and I just feel like I'm not progressing. I even know that I'm not progressing'. He says that he has a 'mood sometimes' when he is hungry and doesn't 'have enough energy to talk'.

At weekends, Kwame says he eats breakfast, such as toast and jam, 'if I see it [food] there', adding, 'cos it's not all the time it comes in, it's like sometimes not there. If it's there then you're lucky'. Sometimes he eats coco-pops but he says 'it gets so boring so I just don't want to eat that food. Sometimes if I look at it yeah I just don't want to look at it anymore'. After school, Kwame says he waits for his friends while they go and buy chicken and chips. Despite some sharing of food, involving his friends offering him some of theirs, he says this is only a bit 'cos it's theirs, only a little bit'. As a result, he says he feels very excluded: 'it feels like I'm left out of the fun that happens and stuff. Like it just makes me feel empty' and 'it makes me feel like, what have I done like, what have I done...?'. Kwame said he wanted help, like 'more from the government' adding 'I don't even know what they're currently doing. It's making my life harder instead of easier'.

\section{Discussion and conclusions}

This above analysis of three cases of young people demonstrates the ways in which food poverty is deeply embedded in the various contexts of their lives - the conditions of their lowincome families, their schools and social lives with friends in the neighbourhood. The cases are illustrative of the multi-layered and multi-dimensional nature of food poverty as experienced by the young people. Media and political discourses generally portray food poverty as synonymous with going without food; the food bank, particularly in media circles, has become a metonym for food poverty in the UK (Knight et al, forthcoming). However, the material from the British study demonstrates the complexity of the experience of food poverty for teenagers including physiological (quantity of food), nutritional (quality), social (alimentary participation) and emotional/psychological dimensions.

Michael, Charley and Kwame all experience going without food at times, Charley less so. Both Michael and Kwame are 15-year-old boys and are likely to need a high calorie intake to meet their needs while growing, a level of food intake not being provided by the families' very limited financial resources. Kwame particularly vividly describes frequent hunger and both the physical effects on his body and how it affects his mood. Michael reports that he is often hungry and looks for food in the cupboard and fridge at lunch time and late at night hoping that food will somehow magically appear. Following Ridge $(2002,2011)$, both Kwame's and Michael's experiences of food poverty have affected their dreams and aspirations: Michael's desire to be a chef has been fuelled by his restricted and monotonous diet and Kwame complains that he is not progressing at school as a result of his hunger and can't afford to attend football training. Although Charley does not mention hunger, she talks about eating at her friend's house and has to go without food for a few hours sometimes. She feels very guilty when her mother skips meals so there is enough for her and her brother. Food poverty is a managed process at the household level, where adults tend to compromise 
their own food intake to protect their children (Tarasuk, 2001); this analysis demonstrates the emotional ramifications as well as physical effects (Connell, 2005) of this strategy. Furthermore, both Michael and Kwame mention changes in family income, access to pocket money and the availability of food at home, thereby reflecting an important temporal dimension of their experiences.

All three young people fill up on cheap manufactured breakfast cereals, such as Weetabix and coco-pops and they eat a lot of sliced bread. While Michael reports eating fruit often, Kwame, in contrast, said he had not eaten fruit for four months. The cases therefore show that when the food is particularly in short supply, the quality as well as the quantity of the food they consume is compromised. Although both Charley and her mother are keen to eat healthily and enjoy cooking and eating different sorts of vegetables and fruit as well as protein, they are clear that this cannot always be achieved on a very limited income. Both Michael's and Charley's mothers rely on frozen food, such as cheap pizza or burgers, and Kwame's diet often lacks protein as he fills up on rice with tomatoes. However, Michael's mother is keen to emphasise that while she provides many vegetables with her meals, Michael prefers to eat differently, and has to cook two different meals most evenings. Michael describes a desire for a high carbohydrate diet; he needs to feel 'full up', but often does not. In addition to some poor quality food, both Michael and Kwame describe the monotony of their diet, saying either that it is boring or that they eat the same food most days, adding to their sense of dissatisfaction.

In addition to being affected by food poverty concerning both quantity and quality, all three young people describe experiences of social exclusion, both at school and outside the home with friends. For Michael, socialising in an area where gentrification over the past 20 years or so has seen increasing middle-class affluence, reflected in pricey cafes and organic food shops, going out with friends locally and participating fully in a social life with them has been even harder for him than it might otherwise have been. Coming home at lunchtime during the school day to have something to eat, such as a bowl of instant noodles, is one way he manages a situation in which he cannot join his friends who buy paninis in the local cafes. Similarly, Kwame describes being left out of the fun when his friends are buying food after school and Charley often misses out on buying food and drink when socialising.

Interestingly, all three young people report how their friends share but only in a limited way: Charley is offered some of 'toastie' in Costa by a friend who then 'forgets' and eats it all herself, while Kwame's friends offer only 'a bit... cos it's theirs'. And despite understanding he hasn't much money, Michael's friends' generosity has limits; they buy things, Michael reports, 'but not all the time, they don't just like blow out all their money'.

We know that children and young people actively contribute to and shape their family's food practices (Fram et al, 2011; O'Connell and Brannen, 2016) and the cases presented here and the study as a whole add weight to that evidence. Michael prepares his own food later in the evening after the meal his mother has cooked. Kwame carries out domestic 'duties' such as clearing up which he does every day and, in order to assist his family's situation, he says he prays hard at Church. He said he was going to use the vouchers he received for participating in the study to buy food for a school camping trip. Charley bargain hunts, sometimes with her friends, but mainly for family meals and is very aware of the cost of all the foodstuffs she and the rest of the family consume. She is creative in helping make meals out of discounted foods and assists her family to stretch the restricted food budget. 
Despite strong media and political discourses that people living in poverty are to blame for their plight, in the main, and echoing work with younger children by Fairbrother et al (2012) the young people did not apportion blame to parents for the shortage of money and food. However, amongst the young people, there were differences in how and to what they attributed food poverty. In regard to the three cases presented, both Kwame and Charley emphasised government's responsibility for ensuring that families had enough to eat and that money wasn't removed from people's accounts, reflecting the current commonplace experiences of delayed benefit payments, while Michael was keen to emphasise the role of employment and wages in preventing food poverty.

In the UK, we are living in a period of deep political and economic uncertainty. Leaving the European Union and the accompanying Brexit negotiations, the implementation of further cuts to welfare benefits alongside continued stagnation in wages, higher inflation including food prices and stringent immigration control, the plight of families such as Kwame's, Michael's and Charley's is unlikely to improve. The resulting food poverty and its effects on children's and young people's physical and emotional wellbeing is a matter of grave concern.

\section{Acknowledgements}

The research leading to these results has received funding from the European Research Council under the European Union's Seventh Framework Programme (FP7/2007-2013)/ERC grant agreement $\mathrm{n}^{\circ} 337977$. We are very grateful to the children and parents who generously gave their valuable time to participate in the study and to the anonymous reviewers for helpful feedback on earlier drafts of this paper.

\section{References}

Attree, P. (2006) The social costs of child poverty: a systematic review of the qualitative evidence. Children and Society, 20: 54-66

Connell, C. Lofton, K., Yadrick, K. and Rehner, T. (2005) Children's experiences of food insecurity can assist in understanding its effect on their well-being. Journal of Nutrition. 135: $1683-1690$

Dowler, E, Turner, S and Dobson, B. (2001) Poverty Bites: Food, Health and Poor Families. Child Poverty Action Group, London

End Child Poverty (2016) www.endchildpoverty.org.uk

Fairbrother, H., Curtis, P. and Goyder, E. (2012) Children's understanding of family financial resources and their impact on eating healthily. Heath and Social Care in the Community, 20 (5): $528-536$

Fram, M.S., Frongillo, E.A., Jones, S.J., Williams, R.C., Burke, M.P., DeLoach, KP. And Blake, CE (2011) Children are aware of food insecurity and take responsibility for managing food resources. Journal of Nutrition, 141: 1114-1119

Gomm, R. and Hammersley, M and Foster, P. (2000) Case Study Method. Sage, London

Harvey, K. (2014) Children and parents' experiences of food insecurity in a South London population. University of Reading and Kids Company. 
Knight, A., Brannen, J., O’Connell, R. and Hamilton, L. (forthcoming) How do children and their families experience food poverty according to UK newspaper media 2006-2015? Journal of Poverty and Social Justice.

Lambie-Mumford, H. and Green, M. (2015) Austerity, welfare reform and the rising use of food banks by children in England and Wales. Area, 1-7

Maguire, E. Burgoine, T. and Monsivais, P. (2015). Area deprivation and the food environment over time: A repeated cross-sectional study on takeaway outlet density and supermarket presence in Norfolk, UK, 1990-2008. Health \& Place 33: 142-147.

O'Connell, R. (2013) The use of visual methods with children in a mixed methods study of family food practices. International Journal of Social Research Methodology, 16 (1): 31-46.

O’Connell, R. and Brannen, J. (2016) Food, Families and Work. Bloomsbury, London

O'Connell, R. and Brannen, J. (in press, 2018). Food poverty and the families the state has turned its back on: the case of the UK. In H. P. Gaisbauer, G. Schweiger \& C. Sedmak (eds). Absolute Poverty in Europe: Interdisciplinary Perspectives on a Hidden Phenomenon. Springer.

O’Connell, R., Owen, C., Padley, M., Simon, A. and Brannen, J. (in press, 2018). Which types of family are at risk of food poverty in the UK? A relative deprivation approach. Social Policy and Society.

Pfeiffer, S., Ritter, T. and Hirseland, A. (2011) Hunger and nutritional poverty in Germany: quantitative and qualitative empirical insights. Critical Public Health, 21 (4): 417-28

Ridge, T. (2002) Childhood Poverty and Social Exclusion: From a Child's Perspective. Policy Press, Bristol

Ridge, T. (2011) The everyday costs of poverty in childhood: a review of qualitative research exploring the lives and experiences of low income children in the UK. Children and Society, 25: 73-84.

Ridge, T. (2013) 'We are All in this together?' The Hidden costs of poverty, recessions and austerity policies on Britain's poorest children'. Children and Society, 27: 406-417.

Royal College of Paediatrics and Child Health (2017) Poverty and child health. Views from the frontline. Child Poverty Action Group and RCPCH, London.

Sharma, N. (2007) It doesn't happen here. The reality of child poverty in the UK. Barnardos, Barkingside

Stone, D. (1988) Policy Paradox and Political Reason. Scott Foresman and Company, Glenview, IL, 
Tarasuk, V. (2001) Discussion Paper on Household and Individual Food Insecurity. Health Canada. Available at: http://hc-sc.gc.ca/fn-an/alt_formats/hpfb-

dgpsa/pdf/nutrition/food_sec_entire-sec_aliments_entier-eng.pdf

Townsend, P. (1979) Poverty in the United Kingdom. Penguin, Harmondsworth:

Wills, W. (2008) 'If the food looks dodgy I dinnae eat it': Teenagers' accounts of food and eating practices in socio-economically disadvantaged families. Sociological Research Online $13(1) 15$.

' Job Seekers Allowance is a benefit paid to people who are unemployed but deemed capable of work and must demonstrate they are looking for work to claim it. Child tax credit is a means tested benefit designed to help parents with the costs of raising a child, including childcare costs for working parents. Child benefit was previously a universal benefit but since January 2013 is means tested where a parent earns over $£ 50,000$ per year. Housing benefit helps with the costs of renting for those on a low income.

"Iceland is a UK supermarket chain selling mainly frozen and low-cost foods

iii Costa Coffee is Britain's largest coffee house chain 